\title{
AVALIAÇÃO DA SUCULÊNCIA E DA SOLUBILIZAÇÃO DE PECTINAS EM MAÇÃS 'GALA' ARMAZENADAS EM ATMOSFERA CONTROLADA, EM FUNÇÃO DE DIFERENTES PRESSÕES PARCIAIS DE $\mathrm{O}_{2} \mathrm{E} \mathrm{CO}_{2}{ }^{1}$
}

\author{
Evaluation of juiciness and pectins solubilization in 'Gala' apples, \\ stored in controlled atmosphere, in function of different partial pressures of $\mathrm{O}_{2}$ and $\mathrm{CO}_{2}$ \\ Rosangela Lunardi ${ }^{2}$, Auri Brackmann ${ }^{3}$, Daniel Alexandre Neuwald ${ }^{4}$, \\ Jocemar Francisco Zanatta ${ }^{5}$, Jorge Adolfo da Silva $^{6}$, Cesar Valmor Rombaldi ${ }^{7}$
}

\section{RESUMO}

Objetivou-se com este trabalho avaliar o efeito de pressões parciais de $\mathrm{O}_{2}$ e $\mathrm{CO}_{2}(1,0 \mathrm{kPa}+2,5 \mathrm{kPa}, 1,0 \mathrm{kPa}+2,0 \mathrm{kPa}$, $0,8 \mathrm{kPa}+2,0 \mathrm{kPa}, 0,8 \mathrm{kPa}+2,5 \mathrm{kPa}$ e 20,8 kPa+0,03 kPa, respectivamente) em maçãs 'Gala' (Malus domestica Baumg.) armazenadas por 8 meses em atmosfera controlada (AC) sobre a perda de suculência, firmeza de polpa, conteúdo de pectina solúvel (PS) e atividade das enzimas pectinametilesterase (PME) e poligalacturonase (PG). A temperatura de armazenamento foi de $0,5^{\circ} \mathrm{C}$ e umidade relativa do ar, em torno de $96 \%$. Ao final do período em AC e mais 7 dias a $20^{\circ} \mathrm{C}$, foram avaliadas a suculência, firmeza de polpa, conteúdo de PS e atividades da PME e PG. As pressões parciais de $1,0 \mathrm{kPa}$ de $\mathrm{O}_{2}+2,0 \mathrm{kPa}$ de $\mathrm{CO}_{2}$ e $0,8 \mathrm{kPa}$ de $\mathrm{O}_{2}+2,0 \mathrm{kPa}$ de $\mathrm{CO}_{2}$ conferiram maior suculência após 8 meses em AC; e as maçãs mais firmes foram as mais suculentas, independente da concentração da atmosfera.

Termos para indexação: Malus domestica, conservação, firmeza de polpa, qualidade.

\section{ABSTRACT}

The objective of this research was to evaluate the effect of $\mathrm{O}_{2}$ and $\mathrm{CO}_{2}$ partial pressures $(1.0 \mathrm{kPa}+2.5 \mathrm{kPa} ; 1.0$ $\mathrm{kPa}+2.0 \mathrm{kPa} ; 0.8 \mathrm{kPa}+2.0 \mathrm{kPa} ; 0.8 \mathrm{kPa}+2.5 \mathrm{kPa}$ and $20.8 \mathrm{kPa}+0.03 \mathrm{kPa}$, respectively) in apples 'Gala' (Malus domestica Baumg.) stored by 8 months in controlled atmosphere (CA) on the juiciness loss, flesh firmness, soluble pectin content (SPC) and activities of pectinmethylesterase (PME) and polygalacturonase (PG). The storage temperature was $0.5^{\circ} \mathrm{C}$ and relative humidities around $96 \%$. At the end of the CA period in and 7 more days at $20^{\circ} \mathrm{C}$ were evaluated the juiciness, flesh firmness, SPC, PME and PG. The partial pressures of $1.0 \mathrm{kPa} \mathrm{O}$ and $2.0 \mathrm{kPa} \mathrm{CO}_{2}$ or $0.8 \mathrm{kPa} \mathrm{O}_{2}$ and $2.0 \mathrm{kPa} \mathrm{CO}_{2}$ were more juicy after 8 months in $\mathrm{CA}$; firmer apples were more juicy independent by of the concentration of the atmosphere.

Index terms: Malus domestica, conservation, flesh firmness, quality.

(Recebido para publicação em 7 de maio de 2003 e aprovado em 15 de agosto de 2003)

\section{INTRODUÇÃO}

A maçã (Malus domestica Baumg.) tem grande importância comercial, ocupando o terceiro lugar no consumo nacional de frutas (MAPA, 2002) e, ao contrário da maioria das frutas, pode ser armazenada por vários meses, assegurando o suprimento do mercado praticamente durante o ano todo. A 'Gala', que é a princi- pal cultivar em exploração no Brasil (ABPM, 2002), apresenta sério problema com perda de suculência, que pode ser considerado um entrave para um armazenamento mais prolongado.

A perda de suculência em maçãs foi descrita como um efeito causado pela separação das células, ou seja, um fruto é menos suculento quando as células do tecido facilmente se separam umas das outras

\footnotetext{
1. Parte da tese desenvolvida pelo primeiro autor para obtenção do grau de Doutor em Ciências, Universidade Federal de Pelotas/UFPel - 96010-900 - Pelotas, RS.

2. Engenheira Agrônoma, Doutora em Ciências/UFPel.

3. Engenheiro Agrônomo, Dr., Professor do Departamento de Fitotecnia, Universidade Federal de Santa Maria/UFSM - $97119-900$ - Santa Maria, RS Autor para correspondência. brackman@creta.ufsm.br

4. Engenheiro Agrônomo, aluno do Curso de Pós-graduação em Agronomia/UFSM.

5. Aluno do Curso de Agronomia/UFPel, bolsista PIBIC/CNPq.

6. Engenheiro Agrônomo, Dr., Pesquisador no Departamento de Ciência e Tecnologia Agroindustrial/UFPel.

7. Engenheiro Agrônomo, Dr., Professor do Departamento de Ciência e Tecnologia Agroindustrial/UFPel.
} 
e a parede celular não se rompe, mesmo sob pressão. Em outras palavras, se a parede celular for mais fraca que a lamela média, ela irá romper-se e o suco será liberado, resultando em fruto suculento (SMEDT et al., 1998).

Em muitos estudos, têm sido demonstrados os efeitos benéficos do armazenamento em câmaras de atmosfera controlada (AC) sobre a qualidade dos frutos. Plocharski e Konopacka (1999) observaram que maçãs armazenadas em AC estavam mais suculentas e com a firmeza mais elevada do que aquelas armazenadas em frio convencional.

$\mathrm{O}$ armazenamento de maçãs em condições de baixa concentração de $\mathrm{O}_{2}$ e elevada de $\mathrm{CO}_{2}$ diminui a perda da firmeza da polpa (LAU et al., 1984), pois a AC reduz a atividade das enzimas responsáveis pela degradação dos componentes da parede celular e lamela média (KADER, 1989). O incremento no conteúdo de pectina solúvel, durante o amadurecimento de maçãs, é menor no armazenamento em AC do que em condições normais na composição da atmosfera (KNEE, 1975). A redução da concentração de $\mathrm{O}_{2}$ também mantém a acidez e reduz a degradação da clorofila da epiderme, além de reduzir a ocorrência de escaldadura e escurecimento da polpa (BRACKMANN et al., 1998). Há, no entanto, uma tendência mundial em utilizar concentrações ultrabaixas de $\mathrm{O}_{2}$ (ULO) para manter a qualidade e prolongar o período de armazenamento de maçãs. $\mathrm{O}$ uso de baixas concentrações de $\mathrm{O}_{2}$ exige um controle rígido das concentrações de $\mathrm{CO}_{2}$, pois níveis de $\mathrm{CO}_{2}$ mais elevados que de $\mathrm{O}_{2}$ podem causar desordens internas nos frutos (MEHERIUK, 1993).

$\mathrm{O}$ uso de $\mathrm{CO}_{2}$ poderá ser benéfico ou prejudicial ao fruto, dependendo da sensibilidade do tecido, concentração usada, período de exposição ao $\mathrm{CO}_{2}$ e temperatura de armazenamento. Concentrações elevadas de $\mathrm{CO}_{2}$ mantêm uma maior firmeza de polpa durante o armazenamento de maçãs (BRACKMANN et al., 2000b), inibindo a respiração do fruto (BRACKMANN et al., 1994), mas também podem causar a degenerescência interna em maçãs, uma vez que níveis tóxicos de $\mathrm{CO}_{2}$ resultam na produção de acetaldeído e etanol (GRAN e BEAUDRY, 1993).

As concentrações de $\mathrm{O}_{2}$ e $\mathrm{CO}_{2}$ adequadas para o armazenamento da maçã 'Gala' diferem em função do local e ano pesquisado. No Brasil, é recomendada a pressão parcial de 1,5 a 2,0 $\mathrm{kPa}$ de $\mathrm{O}_{2}$ e $2,5 \mathrm{kPa}$ de $\mathrm{CO}_{2}$ e temperatura de $1^{\circ} \mathrm{C}$ a $2^{\circ} \mathrm{C}$ (MEHERIUK, 1993). Na temperatura entre $0^{\circ} \mathrm{C}$ e $1^{\circ} \mathrm{C}$, na pressão parcial de
$1 \mathrm{kPa}$ de $\mathrm{O}_{2}$ e $3 \mathrm{kPa}$ de $\mathrm{CO}_{2}$, os frutos apresentaram uma maior qualidade de consumo após 8 meses de armazenamento (BRACKMANN et al., 1994; BRACKMANN e SAQUET, 1995). Na temperatura de $0,5^{\circ} \mathrm{C}$, durante 9 meses de armazenamento, a melhor pressão parcial é de $1 \mathrm{kPa}$ de $\mathrm{O}_{2}$, na presença de 3 a $4 \mathrm{kPa}$ de $\mathrm{CO}_{2}$ (BRACKMANN et al., 2000a).

Tendo em vista o grande potencial nacional de armazenamento em atmosfera controlada e a necessidade de oferta de maçã 'Gala', por um período mais prolongado, objetivou-se avaliar o efeito de diferentes concentrações de $\mathrm{O}_{2}$ e $\mathrm{CO}_{2}$ sobre a qualidade de maçãs 'Gala'.

\section{MATERIAL E MÉTODOS}

Os experimentos foram desenvolvidos no Núcleo de Pesquisa em Pós-colheita (NPP) do Departamento de Fitotecnia da Universidade Federal de Santa Maria (UFSM) e no Laboratório de Biotecnologia do Departamento de Ciência e Tecnologia Agroindustrial da Universidade Federal de Pelotas (UFPel), durante os anos de 2001 e 2002. Foram utilizadas maçãs da cultivar Gala, provenientes de um pomar comercial da empresa Schio, de Vacaria, RS. No momento da colheita, a firmeza de polpa era de 73,3N. Antes da instalação do experimento, os frutos foram selecionados, eliminandose aqueles com lesões e baixo calibre, homogeneizandose as amostras experimentais.

Os frutos foram armazenados em minicâmaras de atmosfera controlada (AC) com volume de 232 litros, as quais foram conectadas por tubulações plásticas a um sistema de controle automático da concentração dos gases $\mathrm{O}_{2}$ e $\mathrm{CO}_{2}$. As minicâmaras permaneceram no interior de uma câmara frigorífica de $45 \mathrm{~m}^{3}$, com sistema de refrigeração por ar forçado, na temperatura de $0,5^{\circ} \mathrm{C}$.

As atmosferas foram instaladas com concentrações de $\mathrm{O}_{2}$ e $\mathrm{CO}_{2}$ de: $1,0 \mathrm{kPa}$ de $\mathrm{O}_{2}+2,5 \mathrm{kPa}$ de $\mathrm{CO}_{2}$, $1,0 \mathrm{kPa}$ de $\mathrm{O}_{2}+2,0 \mathrm{kPa}$ de $\mathrm{CO}_{2}, 0,8 \mathrm{kPa}$ de $\mathrm{O}_{2}+2,0$ $\mathrm{kPa}$ de $\mathrm{CO}_{2}$ e $0,8 \mathrm{kPa}$ de $\mathrm{O}_{2}+2,5 \mathrm{kPa}$ de $\mathrm{CO}_{2}$. O tratamento testemunha foi armazenado em ambiente (20,8 $\mathrm{kPa}$ de $\mathrm{O}_{2}+0,03 \mathrm{kPa}$ de $\mathrm{CO}_{2}$ ). As pressões parciais iniciais de $\mathrm{O}_{2}$ foram obtidas pelo princípio da diluição do $\mathrm{O}_{2}$, com a injeção de nitrogênio $\left(\mathrm{N}_{2}\right)$. O N $\mathrm{N}_{2}(99,5 \%$ de $\mathrm{N}_{2}+0,5 \%$ de $\mathrm{O}_{2}$ ) foi obtido de um sistema gerador baseado no método do PSA (Pressure Swing Adsorption), com peneira molecular de carbono. As pressões parciais de $\mathrm{CO}_{2}$ foram obtidas por injeção de $\mathrm{CO}_{2}$, provenientes de cilindros de alta pressão. 
Para a manutenção constante das concentrações do $\mathrm{O}_{2}$ e $\mathrm{CO}_{2}$, que continuamente se modificavam em função do processo respiratório dos frutos, foi realizada diariamente uma análise e correção das pressões parciais desses gases. Essa análise foi feita com um controlador automático, marca Kronenberger Systemtechnik. $\mathrm{O}_{2}$ consumido foi reposto mediante injeção de ar atmosférico nas minicâmaras. $\mathrm{O}$ excesso de $\mathrm{CO}_{2}$ foi absorvido por uma solução de hidróxido de potássio $40 \%$, contido em um recipiente hermeticamente fechado, através do qual foram circulados os gases das minicâmaras.

A temperatura foi monitorada diariamente utilizando-se termômetros de mercúrio introduzidos na polpa do fruto. A oscilação foi de $\pm 0,2^{\circ} \mathrm{C}$. A umidade relativa do ar (UR) no interior das minicâmaras permaneceu em torno de $96 \%$.

Após oito meses de armazenamento, em ambos os experimentos, metade das amostras experimentais foi analisada no dia da abertura das câmaras, e o restante, após sete dias de exposição dos frutos a uma temperatura de $20^{\circ} \mathrm{C}\left( \pm 0,5^{\circ} \mathrm{C}\right)$, medido na polpa do fruto, que teve por objetivo simular um período de comercialização dos frutos. Os parâmetros analisados foram os seguintes:

- Firmeza de polpa: determinada com auxílio de um penetrômetro manual, com ponteira de 11 $\mathrm{mm}$ de diâmetro, em dois lados opostos na região equatorial da maçã, onde a epiderme foi previamente retirada.

- Suculência: determinada pela prensagem de $20 \mathrm{~g}$ de polpa de maçã durante 1 minuto, numa prensa pneumática desenvolvida no NPP/UFSM especialmente para esse fim. A amostra foi submetida ao peso de $1.500 \mathrm{~kg}$. A quantidade de suco foi obtida pela diferença do peso inicial da amostra $(20 \mathrm{~g})$ e o peso final (após a prensagem). A suculência foi expressa em porcentagem de suco.

Para as avaliações do conteúdo de pectina solúvel e da atividade das enzimas PME e PG, a polpa foi coletada e rapidamente congelada em nitrogênio líquido e mantida $\mathrm{em}-20^{\circ} \mathrm{C}$ para posteriores análises.

- Conteúdo de pectina solúvel: extraído segundo a técnica descrita por McCready e McCoomb (1952), sendo a determinação realizada colorimetricamente pela reação com carbazol, segundo Bitter e Muir (1962). Os resultados foram expressos em mg de ácidos galacturônicos por $100 \mathrm{~g}$ de polpa.

- Atividade da enzima PME: determinada pela técnica empregada por Ratner et al. (1969). A unidade de atividade enzimática da pectinametilesterase foi con- siderada como sendo a quantidade de enzima capaz de catalisar a desmetilação de pectina correspondente a um nmol de $\mathrm{NaOH}$ por minuto nas condições do ensaio.

- Atividade da PG: extraída de acordo com Pressey e Avants (1973) e Jen e Robinson (1984). A determinação foi feita conforme a técnica de Somogyi, modificada por Nelson (1944). A unidade de atividade enzimática da PG foi definida como a quantidade de enzima capaz de catalisar a formação de um nmol de grupos redutores por minuto sob as condições do ensaio.

$\mathrm{O}$ delineamento experimental utilizado foi inteiramente casualizado, com três repetições. Para a suculência, foram usadas quatro repetições, devido ao menor número de frutos usados para quantificar o valor. A unidade experimental para a determinação da firmeza de polpa foi de 25 frutos, ao passo que, para as demais determinações, a unidade experimental foi de seis frutos. Os resultados obtidos foram submetidos à análise de variância, e as médias foram comparadas pelo teste de Duncan, a 5\% de probabilidade. Os dados em porcentagem foram transformados pela fórmula arc.sen $\sqrt{ } \mathrm{x} / 100$, antes da análise de variância.

\section{RESULTADOS E DISCUSSÃO}

Após oito meses de armazenamento, é desejável que as maçãs ainda estejam com qualidade, suculentas e firmes, mantendo essas características durante o período de prateleira que se segue. Observou-se que ao final dos oito meses em atmosfera controlada (AC), a porcentagem de suco variou de $71,9 \%$, nas maçãs que permaneceram em $1,0 \mathrm{kPa}$ de $\mathrm{O}_{2}+2,5 \mathrm{kPa}$ de $\mathrm{CO}_{2}$, a 79,7\%, nas maçãs em 1,0 $\mathrm{kPa}$ de $\mathrm{O}_{2}+2,0 \mathrm{kPa}$ de $\mathrm{CO}_{2}$ (Tabela 1). Entretanto, após sete dias dos frutos em temperatura de $20^{\circ} \mathrm{C}$, a menor suculência foi observada nas maçãs em armazenamento refrigerado (AR) $(75,2 \%)$, ao passo que as maçãs que permaneceram em $0,8 \mathrm{kPa}$ de $\mathrm{O}_{2}+2,0$ $\mathrm{kPa}$ de $\mathrm{CO}_{2}$ apresentaram-se mais suculentas $(81,3 \%)$, embora não diferindo dos tratamentos com $0,8 \mathrm{kPa}$ de $\mathrm{O}_{2}+2,5 \mathrm{kPa}$ de $\mathrm{CO}_{2}$ e $1,0 \mathrm{kPa}$ de $\mathrm{O}_{2}+$ $2,0 \mathrm{kPa}$ de $\mathrm{CO}_{2}$ (Tabela 1). Pelos valores de porcentagem, ficou evidente que houve um leve incremento na suculência nos frutos após sete dias a $20^{\circ} \mathrm{C}$, talvez pelo avanço do grau de maturação desses frutos. Geralmente, o que ocorre é o contrário, ou seja, um decréscimo no conteúdo de suco enquanto os frutos 
permanecem fora da temperatura de armazenamento, em razão da perda de água por transpiração.

Observou-se que os frutos que permaneceram em $1 \mathrm{kPa}$ de $\mathrm{O}_{2}+2,5 \mathrm{kPa}$ de $\mathrm{CO}_{2}$ apresentaram na saída da câmara menor firmeza e menor suculência, embora a suculência desses frutos não tenha diferido estatisticamente do tratamento com $0,8 \mathrm{kPa}$ de $\mathrm{O}_{2}+2,5 \mathrm{kPa}$ de $\mathrm{CO}_{2}$ (Tabela 1). Houve, nesse caso, possivelmente, um efeito da concentração mais elevada de $\mathrm{CO}_{2}$, o que é prejudicial para a qualidade da maçã. As concentrações de $1 \mathrm{kPa}$ de $\mathrm{O}_{2}+2,5 \mathrm{kPa}$ de $\mathrm{CO}_{2}$ estão muito próximas daquelas recomendadas para a maçã 'Gala' por Brackmann et al. (1994), Brackmann e Saquet (1995) e Saquet et al. (1997), que são $1 \mathrm{kPa}$ de $\mathrm{O}_{2}+3 \mathrm{kPa}$ de $\mathrm{CO}_{2}$.

Os frutos que permaneceram sete dias a $20^{\circ} \mathrm{C}$ apresentaram firmeza de polpa mais elevada que os frutos avaliados na saída da câmara (Tabela 1), contrariando a tendência normal esperada, que é um decréscimo na firmeza após um período de tempo em que os frutos permanecem em temperatura ambiente. Isso, provavelmente, deveu-se ao murchamento dos frutos, que conferiu maior resistência à penetração do êmbolo do penetrômetro na polpa, mascarando os resultados (FORTES e PETRI, 1982).

Os frutos que apresentam menor firmeza de polpa geralmente apresentam menor conteúdo de suco, pois o fruto menos firme tende a estar com a polpa mais farinhenta e mais seca quando comparado a um fruto firme. Segundo Plocharski e Konopacka (1999), não existe correlação entre a firmeza e a suculência. Esses autores observaram, no entanto, que em maçãs armazenadas em AC, a firmeza de polpa e a suculência estavam mais elevadas do que nas maçãs que permaneceram em AR. Os resultados observados na tabela 1 são condizentes com a afirmação feita pelos autores acima citados somente após sete dias a $20^{\circ} \mathrm{C}$, quando os frutos sob AR apresentaram menor suculência que os frutos sob AC.

Segundo Plocharski e Konopacka (1999), a suculência depende provavelmente da preservação da estrutura original das substâncias pécticas, ou seja, da integralidade das cadeias de uronídeos que compõem a pectina. Porém, com o amadurecimento dos frutos, a pectina presente na parede celular e lamela média começa a ser solubilizada, e o fruto perde firmeza (BEN-ARIE et al., 1979). Na Tabela 2 verifica-se que a pectina foi mais solubilizada nos frutos em $\mathrm{AR}$, sem diferir estatisticamente daqueles das concentrações de $1 \mathrm{kPa}$ de $\mathrm{O}_{2}+2,5 \mathrm{kPa}$ de $\mathrm{CO}_{2}$ e 0,8 $\mathrm{kPa}$ de $\mathrm{O}_{2}+2,5 \mathrm{kPa}$ de $\mathrm{CO}_{2}$, quando analisada na saída da câmara. Esses resultados estão de acordo com os observados por vários autores, em que frutos com baixa firmeza de polpa apresentaram maior teor de pectinas solúveis (BEN SHALOM et al., 1996; KETSA e DAENGKANIT, 1999). Após sete dias a $20^{\circ} \mathrm{C}$, o maior teor de pectinas solúveis foi observado também nos frutos em $\mathrm{AR}$, sem diferir significativamente dos frutos em $0,8 \mathrm{kPa}$ de $\mathrm{O}_{2}$.

TABELA 1 - Firmeza de polpa e suculência de maçãs 'Gala' submetidas a diferentes pressões parciais de $\mathrm{CO}_{2} \mathrm{e}$ $\mathrm{O}_{2}$, avaliadas na saída da câmara, após 8 meses de armazenamento e após 7 dias a $20^{\circ} \mathrm{C}$. Santa Maria, 2003.

\begin{tabular}{ccccc}
\hline \multirow{2}{*}{$\begin{array}{c}\text { Pressão parcial de } \mathbf{O}_{2}+\mathbf{C O}_{2} \\
(\mathbf{k P a})\end{array}$} & \multicolumn{2}{c}{ Suculência $(\boldsymbol{\%})$} & \multicolumn{2}{c}{ Firmeza de polpa (N) } \\
\cline { 2 - 5 } & $76,6 \mathrm{ab}$ & $75,2 \mathrm{c}$ & Saída & $\mathbf{7}$ dias \\
\hline $20,8+0,03(\mathrm{AR})$ & $71,9 \mathrm{c}$ & $78,0 \mathrm{~b}$ & $39,0 \mathrm{~b}^{*}$ & $40,9 \mathrm{~b}$ \\
$1,0+2,5$ & $79,7 \mathrm{a}$ & $79,8 \mathrm{ab}$ & $39,3 \mathrm{~b}$ & $59,6 \mathrm{a}$ \\
$1,0+2,0$ & $77,9 \mathrm{ab}$ & $81,3 \mathrm{a}$ & $59,5 \mathrm{a}$ & $68,4 \mathrm{a}$ \\
$0,8+2,0$ & $75,1 \mathrm{bc}$ & $80,5 \mathrm{ab}$ & $53,1 \mathrm{a}$ & $65,6 \mathrm{a}$ \\
$0,8+2,5$ & 3,25 & 2,02 & 10,84 & $61,1 \mathrm{a}$ \\
\hline $\mathrm{CV}(\%)$ & & 55 & 12,55 \\
\hline
\end{tabular}

* Médias seguidas de mesma letra na coluna não diferem entre si pelo teste de Duncan (5\%). 
TABELA 2 - Conteúdo de pectina solúvel e atividade das enzimas pectinametilesterase (PME) e poligalacturonase (PG) em maçãs 'Gala' submetidas a diferentes pressões parciais de $\mathrm{CO}_{2}$ e $\mathrm{O}_{2}$, avaliadas na saída da câmara, após 8 meses de armazenamento e após 7 dias a $20^{\circ} \mathrm{C}$. Pelotas, 2003.

\begin{tabular}{ccccccc}
\hline \multirow{2}{*}{$\begin{array}{c}\text { Pressão parcial de } \mathbf{O}_{\mathbf{2}}+\mathbf{C O}_{\mathbf{2}} \\
(\mathbf{k P a})\end{array}$} & \multicolumn{2}{c}{$\begin{array}{c}\text { Pectina solúvel } \\
(\mathbf{m g} / \mathbf{1 0 0 g})\end{array}$} & \multicolumn{2}{c}{$\begin{array}{c}\text { PME } \\
\left(\mathbf{U}^{* *}\right)\end{array}$} & \multicolumn{2}{c}{$\begin{array}{c}\text { PG } \\
(\mathbf{U} * *)\end{array}$} \\
\cline { 2 - 7 } & Saída & $\mathbf{7}$ dias & Saída & $\mathbf{7}$ dias & Saída & $\mathbf{7 ~ d i a s}$ \\
\hline $20,8+0,03(\mathrm{AR})$ & $61,3 \mathrm{a} *$ & $50,8 \mathrm{a}$ & $582,2 \mathrm{c}$ & $1290,9 \mathrm{~b}$ & $3,13 \mathrm{a}$ & $3,26 \mathrm{c}$ \\
$1,0+2,5$ & $55,0 \mathrm{ab}$ & $41,2 \mathrm{~b}$ & $1822,5 \mathrm{~b}$ & $2936,3 \mathrm{a}$ & $3,72 \mathrm{a}$ & $8,54 \mathrm{a}$ \\
$1,0+2,0$ & $46,6 \mathrm{~b}$ & $38,2 \mathrm{~b}$ & $2759,1 \mathrm{a}$ & $2860,4 \mathrm{a}$ & $3,35 \mathrm{a}$ & $7,97 \mathrm{ab}$ \\
$0,8+2,0$ & $43,2 \mathrm{~b}$ & $44,8 \mathrm{ab}$ & $2936,3 \mathrm{a}$ & $3214,8 \mathrm{a}$ & $4,11 \mathrm{a}$ & $5,69 \mathrm{bc}$ \\
$0,8+2,5$ & $50,3 \mathrm{ab}$ & $44,7 \mathrm{ab}$ & $2480,7 \mathrm{a}$ & $3012,3 \mathrm{a}$ & $3,78 \mathrm{a}$ & $4,83 \mathrm{c}$ \\
\hline $\mathrm{CV}(\%)$ & 11,81 & 8,57 & 15,25 & 8,68 & 14,49 & 23,65 \\
\hline
\end{tabular}

*Médias seguidas de mesma letra na coluna não diferem entre si pelo teste de Duncan (5\%). **1 nmol.g $\mathrm{g}^{-1} \cdot \mathrm{min}^{-1}$ de tecido.

Com relação à atividade das enzimas PME e PG (Tabela 2), observa-se que, na saída da câmara, a atividade da PME foi menor nos frutos em AR, seguido pelas concentrações de $1 \mathrm{kPa}$ de $\mathrm{O}_{2}+2,5 \mathrm{kPa}$ de $\mathrm{CO}_{2}$. Possivelmente, a atividade da PME, nessas concentrações, estava mais baixa que nas outras concentrações de gases, porque estava ocorrendo um decréscimo no substrato, já que a solubilização da pectina também foi maior nesses tratamentos. A atividade da PG, no entanto, não diferiu entre os tratamentos. Já, após sete dias em temperatura ambiente (Tabela 2), foi observada novamente menor atividade da PME nos frutos em AR. O mesmo aconteceu com a atividade da PG, que também foi menor nos frutos em AR, além dos frutos armazenados em $0,8 \mathrm{kPa}$ de oxigênio, e a maior atividade dessa enzima ocorreu nos frutos submetidos a $1,0 \mathrm{kPa}$ de oxigênio. Segundo Zhou et al. (2000b), o armazenamento dos frutos em AC pode reduzir a atividade da PG, pelo efeito do alto $\mathrm{CO}_{2}$ e baixo $\mathrm{O}_{2}$ em inibir a síntese da PG, porém, após um período em temperatura ambiente, ela volta a ser produzida. Foi o que provavelmente aconteceu com os frutos armazenados em AC.

Muitos pesquisadores têm atribuído a perda de firmeza de polpa à atividade da PG (SUZUKI et al., 1991; BONGHI et al., 1996; PATHAK e SANWAL, 1998). Porém, conforme os resultados deste experimento, os frutos que tiveram a menor firmeza de polpa e também os menores conteúdos de suco (Tabela 1) não apresentaram a maior atividade de PG (Tabela 2), nem tampouco a maior atividade da PME, possivelmente porque essa perda de firmeza deveu-se à ação de outras enzimas (TRINCHERO et al., 1999).

A explicação para a lanosidade ou falta de suculência em frutos de caroço, conforme Zhou et al. (2000a, 2000b), é o desbalanço que ocorre entre as enzimas PME e PG, ou seja, a atividade da PME aumenta, ao passo que a atividade da PG diminui, com diminuição da pectina solúvel, à medida que o fruto amadurece. Esse desbalanço provoca a geleificação das pectinas com a adsorção da água. No processo normal de amadurecimento, a enzima PME diminui e a PG aumenta, com aumento da solubilização de pectinas, havendo uma alta relação PG/PME. No entanto, pelos resultados observados neste experimento, não foi possível explicar a falta de suculência das maçãs pelo desbalanço dessas enzimas, pois os frutos que apresentaram menor solubilização das pectinas, maior atividade da PME e menor atividade da PG também apresentaram maior suculência, contradizendo a afirmação dos autores acima citados.

Segundo Harker e Hallett (1992), a principal causa do aspecto de polpa farinhenta e pouco suco é a separação das células que ocorre na região da lamela média em razão da solubilização das pectinas. Nesse caso, a parede celular é mais forte que a lamela média, que não se rompe sob pressão, impedindo, assim, a liberação do suco e resultando em fruto com pouca suculência (SMEDT et al., 1998). Conforme os resultados observados nas Tabelas 1 e 2, os frutos menos suculentos foram os que apresentaram maior solubilização de 
pectinas, concordando com esses autores. No entanto, esses frutos não foram os que apresentaram as maiores atividades das enzimas PME e PG, levando a supor que outras enzimas podem estar também atuando na solubilização de pectinas, como a $\beta$-galactosidase, celulase, entre outras (BARRETT e GONZALEZ, 1994; KETSA e DAENGKANIT, 1999).

\section{CONCLUSÕES}

De acordo com os resultados obtidos na avaliação da maçã 'Gala' após oito meses de armazenamento em atmosfera controlada (AC) e mais sete dias a $20^{\circ} \mathrm{C}$, pode-se concluir que pressões parciais de $1,0 \mathrm{kPa}$ de $\mathrm{O}_{2}$ + 2,0 kPa de $\mathrm{CO}_{2}$ e $0,8 \mathrm{kPa}$ de $\mathrm{O}_{2}+2,0 \mathrm{kPa}$ de $\mathrm{CO}_{2}$ conferem maior suculência que $1,0 \mathrm{kPa}$ de $\mathrm{O}_{2}+2,5 \mathrm{kPa}$ de $\mathrm{CO}_{2}$ e $0,8 \mathrm{kPa}$ de $\mathrm{O}_{2}+2,5 \mathrm{kPa}$ de $\mathrm{CO}_{2}$.

Maçãs com firmeza de polpa mais elevada têm maior suculência, independente da concentração de gases a que foram submetidas.

Frutos com maior solubilização de pectinas são menos suculentos e menos firmes.

Provavelmente as atividades das enzimas pectinametilesterase e poligalacturonase não afetam a falta de suculência em maçãs 'Gala'.

\section{REFERÊNCIAS BIBLIOGRÁFICAS}

ABPM. Informações estatísticas. Disponível em: <http//: www.abpm.org.br>. Acesso em: 01 jun. 2002.

BARRET, D. M.; GONZALEZ, C. Activity of softening enzymes during cherry maturation. Journal of Food Science, Chicago, v. 59, n. 3, p. 574-577, 1994.

BEN-ARIE, R.; KISLEV, N.; FRENKEL, C. Ultrastructural changes in the cell walls of ripening apple and pear fruit. Plant Physiology, Rockville, v. 64, p. 197-202, 1979.

BEN-SHALOM, N.; HANZON, J.; PINTO, R. Cell wall changes and partial prevention of fruit softening in prestorage heat treated 'Anna' apples. Journal of the Science of Food and Agriculture, London, v. 72, n. 2, p. 231-234, 1996.

BITTER, T.; MUIR, H. M. A modified uronic acid carbazole reaction. Analytical Chemistry, New York, v. 34 , p. $330-334,1962$.

BONGHI, C.; PAGNI, S.; VIDHIH, R. Cell wall hydrolases and amylases in kiwifruit softening.
Postharvest Biology and Technology, Amsterdam, v. 9, n. 1, p. 19-29, 1996.

BRACKMANN, A.; MAZARO, S. M.; ARGENTA, L. C. Efeito das temperaturas e condições de armazenamento em atmosfera controlada, sobre a qualidade da maçã cv. Gala. In: CONGRESSO BRASILEIRO DE FRUTICULTURA, 13., 1994, Salvador. Resumos... Salvador: [s.n.], 1994. v. 2, p. 647.

BRACKMANN, A.; MAZARO, S. M.; LUNARDI, R. Armazenamento da maçã cv. Golden Delicious em atmosfera controlada com altas concentrações de $\mathrm{CO}_{2}$ e ultra-baixas de $\mathrm{O}_{2}$. Ciência Rural, Santa Maria, v. 26, n. 2, p. 215-219, 1998.

BRACKMANN, A.; SAQUET, A. A. Armazenamento de maçã cv. Gala em atmosfera controlada. Revista Brasileira de Agrociência, Pelotas, v. 1, n. 2, p. 5560, 1995.

BRACKMANN, A.; STEFFENS, C. A.; WACLAWOVSKY, A. J. Efeito da temperatura e da pressão parcial de $\mathrm{CO}_{2}$ sobre maçã 'Gala' armazenada sob atmosfera controlada contendo pressão parcial ultra-baixa de oxigênio. Ciência e Agrotecnologia, Lavras, v. 24, p. 25-32, 2000a. Edição Especial.

BRACKMANN, A.; WACLAWOVSKY, A. J.; BALZ, G. Tratamentos com altas concentrações de $\mathrm{CO}_{2}$ em maçãs cv. Gala antes do armazenamento em atmosfera controlada. Revista Brasileira de Fruticultura, Jaboticabal, v. 22, p. 82-85, 2000b. Edição Especial.

FORTES, G. R. L.; PETRI, J. L. Distúrbios fisiológi$\cos$ em macieira e seu controle. Florianópolis: EMPASC; ACARESC, 1982. 32 p. (Boletim Técnico, $3)$.

GRAN, C. D.; BEAUDRY, R. M. Modified atmosphere packaging determination of lower oxygen limits for apple fruit using respiratory quotient and ethanol accumulation. In: INTERNATIONAL CONTROLLED ATMOSPHERE RESEARCH CONFERENCE, 6., 1993, New York. Proceedings... New York: [s.n.], 1993. v. 1, p. 54-62.

HARKER, F. R.; HALLETT, I. C. Physiological changes associated with development of mealiness of apple fruit during cool storage. HortScience, Alexandria, v. 27, n. 12, p. 1291-1294, 1992. 
JEN, J. J.; ROBINSON, M. L. P. Pectolytic enzymes in sweet bell peppers (Capsicum annuum L.). Journal of Food Science, Chicago, v. 49, n. 4, p. 1085-1087, 1984.

KADER, A. A. Mode of action of oxygen and carbon dioxide on postharvest physiology of 'Bartlett' pears. Acta Horticulturae, Wageningen, n. 258, p. 161-167, 1989.

KETSA, S.; DAENGKANIT, T. Firmness and activities of polygalacturonase, pectinesterase, $\beta$-galatosidase and cellulase in ripening durian harvest at different stages of maturity. Scientia Horticulturae, Amsterdam, v. 8, p. 181-188, 1999.

KNEE, M. Changes in structural polysaccharides of apples ripening during storage. In: FACTEURS ET RÉGULATION DE LA MATURATION DES FRUITS, 1974, Paris. Proceedings... Paris: [s.n.], 1975. p. 341345.

LAU, O. L.; LIU, Y.; YANG, S. F. Influence of storage atmospheres and procedures on 1-aminocyclopropane1-carboxylic acid concentration in relation to flesh firmness in 'Golden Delicious' apple. HortScience, Alexandria, v. 19, n. 3, p. 425-426, 1984.

McCREADY, R. M.; McCOOMB, E. A. Extraction and determination of total pectic materials in fruits. Analytical Chemistry, Washington, v. 24, n. 12, p. 1586-1588, 1952.

MEHERIUK, M. CA storage conditions for apples, pears and nashi. In: CA'93, INTERNATIONAL CONTROLLED ATMOSPHERE RESERCH CONFERENCE, 6., 1993, New York. Proceedings... New York: [s.n.], 1993. v. 2, p. 832.

MINISTÉRIO DA AGRICULTURA, PECUÁRIA E ABASTECIMENTO. Anuário Brasileiro de Fruticultura: principais frutas: Maçã. Brasília, 2002. 176 p.

NELSON, N. A. A photometric adaptation of Somogyi method for the determination of glucose. Journal of Biological Chemistry, Baltimore, v. 135, n. 1, p. 136$175,1944$.

PATHAK, N.; SANWAL, G. G. Multiple forms of polygalacturonase from banana fruits. Phytochemistry, Oxford, v. 48, n. 2, p. 249-255, 1998.
PLOCHARSKI, W. J.; KONOPACKA, D. The relation between mechanical and sensory parameters of apples and pears. Acta Horticulturae, Wageningen, n. 485, p. 309-317, 1999.

PRESSEY, R.; AVANTS, J. K. Separation and characterization of the exopolygalacturonase and endopolygalacturonase from peaches. Plant Physiology, Baltimore, v. 52, n. 3, p. 252-256, 1973.

RATNER, A. R.; GOREN, R.; MONSELISE, S. Activity of pectin esterase and cellulase in the abscission zone of citrus leaf explants. Plant Physiology, Washington, v. 44, n. 12, p. 1717-1723, 1969.

SAQUET, A. A.; BRACKMANN, A.; STORCK, L. Armazenamento de maçã 'Gala' sob diferentes temperaturas e concentrações de oxigênio e gás carbônico. Ciência Rural, Santa Maria, v. 27, n. 3, p. 399-405, 1997.

SMEDT, V. de; PAUWELS, E.; BAERDEMAEKER, J. de; NICOLAÏ, B. Microscopic observation of mealiness in apples: a quantitative approach. Postharvest Biology and Technology, Amsterdam, v. 14, n. 2, p. 151-158, 1998.

SUZUKI, K.; YOSINAGA, T.; KANEKO, A. Studies on the ripening acceleration of vapor-heat treated papaya. Journal of the Japanese Society for Food Science and Technology, Tokyo, v. 38, n. 11, p. 10571062, 1991.

TRINCHERO, G. D.; SOZZI, G. O.; CERRI, A. M. Ripening-related changes in ethylene production, respiration rate and cell-wall enzyme activity in goldenberry (Physalis peruviana L.), a solanaceous species. Postharvest Biology and Technology, Amsterdam, v. 16, n. 2, p. 139-145, 1999.

ZHOU, H. W.; BEN-ARIE, R.; LURIE, S. Pectin esterase, polygalacturonase and gel formation in peach pectin fractions. Phytochemistry, Oxford, v. 55, p. 191-195, 2000a.

ZHOU, H. W.; LURIE, S.; LERS, A.; KHATCHITSKI, A.; SONEGO, L.; BEN-ARIE, R. Delayed storage and controlled atmosphere storage of nectarines: two strategies to prevent woolliness. Postharvest Biology and Technology, Amsterdam, v. 18, n. 2, p. 133-141, 2000 b. 